\title{
Profile and client satisfaction among clients of Integrated Counselling and Testing Centre for human immunodeficiency virus in Delhi
}

\section{Vinoth Gnana Chellaiyan, Deepak K. Raut', Anita Khokhar', Saudan Singh ${ }^{1}$}

Assistant Professor, Departments of Community Medicine,

Madha Medical College and

Research Institute, Chennai,

1VMMC and Safdarjung Hospital,

New Delhi, India

Address for the Correspondence: Dr. Vinoth Gnana Chellaiyan, Assistant Professor, Department of Community Medicine, Madha

Medical College and Research

Institute, Chennai-122, India.

E-mail: drchellaiyan@gmail.com

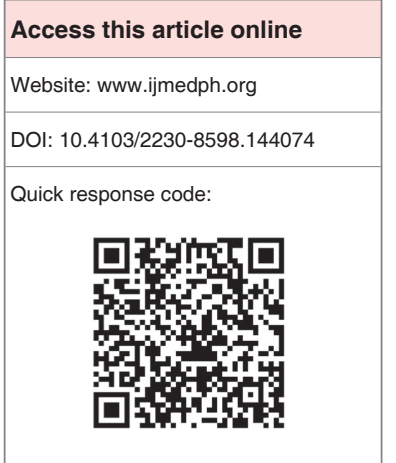

Background: Integrated Counseling and Testing Centre (ICTC) is a place where a person is counseled and tested for human immunodeficiency virus (HIV) and also a key entry point to the prevention of HIV infection and treatment of HIV infected people. The ICTC services are cost-effective and noncoercive intervention in the prevention of HIV/AIDS. The satisfaction of the clients availing these services indicates the quality of the services provided. Objective: The objective was to study the profile and satisfaction of clients attending counseling services of integrated counseling and testing centers in Delhi. Materials and Methods: The study was a descriptive, cross-sectional, health facility based study. The study was done in 20 ICTCs of Delhi. The ICTCs were chosen on the basis of population proportion to size. Consecutive sampling method was followed for recruiting the clients. After obtaining written consent, exit interview of 300 clients was undertaken. Results: Among 300 clients, $204(68 \%)$ were males, and 96 (32\%) were females. Majority, 267 (89\%) of the clients were staying with family and $33(11 \%)$ were staying with friends/roommates. The total number of referred clients was $270(90 \%)$ and self-referred or direct walk-in client was 30 (10\%). Among the direct walk-in/self-referred clients, $12(40 \%)$ clients were recommended by their friends to come, $4(13.3 \%)$ clients seek to avail ICTC services because of high risk behavior and $14(46.7 \%)$ clients wanted to get tested for HIV as their spouse was HIV positive. About $96.3 \%$ of the clients who attended the counseling services were found to be satisfied. Conclusion: The proportion of self-referred/direct walk-in clients was very low, and low level of awareness about the HIV test and counseling services was found among the clients. This reflects the need to enhance the efforts directed at increasing the awareness of HIV test and counseling services. The satisfaction of clients could be further improved by better counseling sessions.

Key words: Client satisfaction, human immunodeficiency virus counseling, integrated Counseling and Testing Centre

\section{INTRODUCTION}

Human immunodeficiency virus (HIV) is a global pandemic and has been a serious public health concern due to its soaring magnitude. In India, HIV continues as a notable health problem with an adult prevalence of $0.31 \% \cdot{ }^{\left[{ }^{[1]}\right.} \mathrm{HIV}$ counseling and testing services are key entry point in prevention of HIV infection, treatment and care of people who are infected with HIV. When availing counseling and testing services, people can access accurate information about HIV prevention and undergo HIV test in a supportive and confidential environment. ${ }^{[2]}$ In most of the developed countries, assessing patient satisfaction has been a part of evaluation of health care delivery system. ${ }^{[3]}$ In India, studies have been done on patients satisfaction in directly observed treatment short course (DOTS) center and primary health care settings. ${ }^{[4]}$ Patient satisfaction is an patient perspective that reflects the quality of health services. ${ }^{[3]}$ Measuring patient satisfaction would help in assessment of performance of health care service delivery. ${ }^{[5]}$ The present study was undertaken to interview the clients who were availing the counseling services. The objective was to study the profile and satisfaction of clients attending counseling services in integrated counseling and testing centers in Delhi. 


\section{MATERIALS AND METHODS}

\section{Study population}

The study was conducted in integrated Counseling and Testing Centers (ICTCs) of Delhi, India. There were 75 ICTCs in public health sector of Delhi at the time of the study (as of March 2011). This is excluding 16 Prevention of Parent to Child Transmissions, which were exclusively for antenatal clients and were having separate reporting system with the State AIDS Control Society. The clients attending the ICTCs were the study population.

\section{Study design and sampling}

The study was a descriptive, cross-sectional, facility based study. Twenty ICTCs out of 75 ICTCs were selected on the basis of probability proportion to size, that is on the basis of number of clients' catered by ICTCs in the year 2011. Sample size was calculated taking the prevalence of $90 \%$ client satisfaction found in previous study ${ }^{[6]}$ To reduce the homogeneity of responses of the clients from the selected 20 ICTCs, design effect was used allowing the cluster design structure of ICTCs. A nonresponse rate of 5\% was expected (based on response obtained during pilot study) and was considered during the sample size calculation. The calculated sample size was 300. Hence, 20 clients per selected ICTCs were interviewed.

\section{Data collection tool}

The study instrument used in the study was tools for evaluating HIV voluntary counseling and testing by UNAIDS. ${ }^{[7]}$ In the study tool, client satisfaction component was used for assessing client satisfaction. This tool was a generic tool, which had been standardized and validated. The tool for assessing client satisfaction was modified with addition of Likert scale with eight statements. Relevant sociodemographic details of clients were also collected. The client satisfaction questionnaire was translated into local language (Hindi). This was back translated to English by another person.

\section{Data collection procedure}

Pretesting of the questionnaire was done in 45 clients in two ICTCs, which were not part of main study and corrections were made. Consecutive sampling method was done for selecting clients, as the interview of the clients was done in outpatient department. The clients who had attended the counseling, willing to participate in the study were included in the study. The data collection was done from January 2012 to December 2012.

\section{Measures}

For statements of client satisfaction, scoring was given on a five point Likert scale (strongly disagree and disagree, neutral, agree and strongly agree). Reverse Likert scale was used for the statements that indicated dissatisfaction. The statements were given scores:

1. Disagree and strongly disagree,

2. Neutral,

3. Agree and strongly agree.
The total maximum score of eight statements were 24 . The client satisfaction were graded as satisfied (score $>16$ ) and not satisfied (score <16).

\section{Data entry and analysis}

The data collected were analyzed with SPSS version 20.0 (SPSS, IBM). Questionnaires were checked for completeness and correctness before entering into the worksheet. Data validation checks were performed at a regular interval for data entered into the worksheet of Microsoft Excel (Microsoft Corporation). Significance of difference in proportions (qualitative variables) was calculated using Chi-square test. Significance of $P$ value was taken if $P<0.05$.

\section{Ethical consideration}

The interview was undertaken only after obtaining written consent from the clients. Confidentiality of the clients was maintained at all points of study. There was no mention of name or complete address of the client anywhere in the interview schedule. The study was approved by Institutional Ethical Review Board of Safdarjung Hospital, New Delhi. Permission to conduct the study was obtained from project director, Delhi State AIDS Control Society, Delhi.

\section{RESULTS}

\section{Sociodemographic profile of the clients}

A total of 300 clients were interviewed, among which 204 (68\%) were males, and 96 (32\%) were females with male:female of 2.1:1 [Table 1]. There were no refusals from the clients. The age of the clients ranged from 12 years to 60 years with a mean (standard deviation)

\begin{tabular}{lc} 
Table 1: Sociodemographic profile of the clients \\
attending ICTCs in Delhi $(\boldsymbol{n}=\mathbf{3 0 0})$ \\
\hline \multicolumn{2}{l}{ Sociodemographic profile } \\
\hline Gender \\
Male \\
Female \\
Religion & $204(68)$ \\
Hindus & $96(32)$ \\
Muslims & \\
Sikhs & $267(89)$ \\
Marital status & $22(7.3)$ \\
Married & $11(3.7)$ \\
Single & \\
Living status & $182(60.7)$ \\
Living with family & $118(39.3)$ \\
Living with friends/roommates & \\
Occupation & $267(89)$ \\
Unskilled and agriculture & $33(11)$ \\
Housewife & \\
Business & $88(29.3)$ \\
Student & $68(22.7)$ \\
Service class people & $60(20.0)$ \\
Truck/auto/taxi drivers and cleaners & $28(9.3)$ \\
Unemployed & $21(7.0)$ \\
\hline ICTC = Integrated Counseling and Testing Center & $20(6.7)$ \\
\end{tabular}


of 29 ( \pm 7.9$)$. Maximum clients, $122(40.7 \%)$ were in the age group of 20-29 years. Among the 300 clients, 200 (66.7\%) had education till fifth class, 54 (18\%) had education up to higher secondary class, $16(5.3 \%)$ were graduates, and $26(8.7 \%)$ were illiterates. Among the women, majority 68 (70.8\%) were housewives.

\section{Time spent in availing the services}

The clients stated that mean time spent in locating the ICTC site was $11 \mathrm{~min}$; however it ranged between 1 and $30 \mathrm{~min}$. The mean time period spent in waiting to see the counselor was $17 \mathrm{~min}$ (5-60 $\mathrm{min}$ ) and the mean time duration spent in the counseling session was $7 \mathrm{~min}$ (2-20 min).

\section{Reason to attend integrated Counseling and Testing Centre}

The total number of referred clients was 270 (90\%) and selfreferred or direct walk-in clients were $30(10 \%)$ [Figure 1]. Among the direct walk-in/self-referred clients, 12 (40\%) clients reported that their friends recommended them to come ICTC, $4(13.3 \%)$ clients seek to avail ICTC services because of their high risk behavior and $14(46.7 \%)$ clients wanted to get tested for HIV as their spouse was HIV positive. Among the facility referred clients, majority, $176(65.2 \%)$ of the clients had been referred from tuberculosis clinic/DOTS center, followed by referral from other departments. Among the 94 (34.8\%) clients referred from other departments, majority $49(18.2 \%)$ clients were from Department of Surgery followed by Gynecology 29 (10.7\%) and Medicine 16 (5.9\%) Departments [Table 2].

\section{Perspective of the clients about the counseling}

Most of the clients, 291 (97\%) said that they did not feel hesitant in expressing themselves to counselors, while $9(3 \%)$ clients said that they felt hesitant or unable to express due to reasons-counselor was of opposite gender 5 (1.7) and difficulty in understanding counselors, language $4(1.3 \%)$. Among the clients who attended the posttest counseling, $24(61.5 \%)$ clients said that they were able to meet the same counsellor before and after HIV testing.

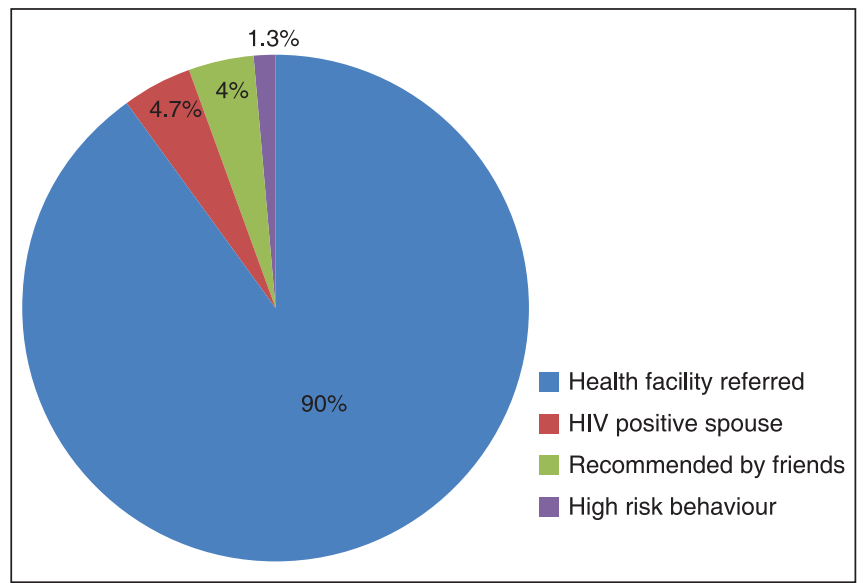

Figure 1: Distribution of clients according to the reasons for attending the counseling session at integrated Counseling and Testing Centre $(n=300)$

\section{Satisfaction of the clients}

Two hundred and eighty nine $(96.3 \%)$ clients who attended the counseling services scored $>16$ and were found to be satisfied [Table 3 and Figure 2].

The client satisfaction score was analyzed with the referral status of the clients (facility referred and self-referred) to find the differences in the mean scores between the groups. However, the difference found was not statistically significant $(P=0.447)$ [Table 4].

\section{DISCUSSION}

Among the 300 clients, only 10\% (30) clients were self-referred and $90 \%$ (270) clients were facility referred/provider initiated. This figure is lesser than the national average ${ }^{[1]}$ in which the client initiated/selfreferred were $31.4 \%$. Similar results were found in a study done by Papanna et al. with $89 \%$ provider initiated clients. ${ }^{[8]}$ The proportion of provider initiated clients in other studies varied between $11 \%$ and

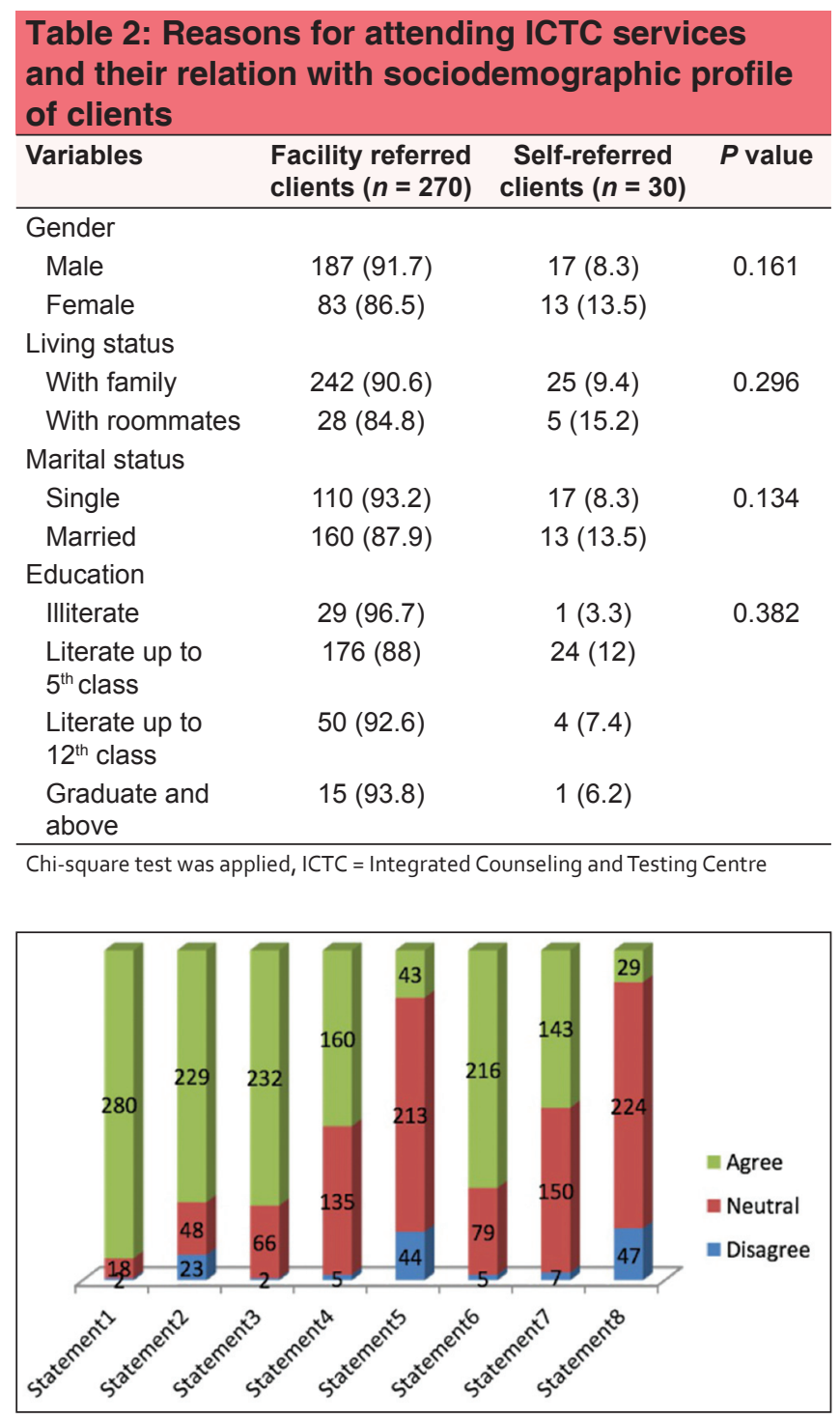

Figure 2: Distribution of statements of client satisfaction $(n=300)$ 


\begin{tabular}{|c|c|c|c|}
\hline \multirow[t]{2}{*}{ Client satisfaction statements $(n=300)$} & Disagree & Neutral & Agree \\
\hline & $\overline{\text { Frequency (\%) }}$ & $\overline{\text { Frequency }(\%)}$ & Frequency (\%) \\
\hline The counselor showed interest in explaining issues pertaining to HIV that I was not aware of & $2(0.7)$ & $18(6)$ & $280(93.3)$ \\
\hline During the session I was given the opportunity to ask questions and clarify my doubts & $23(7.7)$ & $48(16)$ & $229(76.3)$ \\
\hline The counseling provided to me was very useful and helpful & $2(0.7)$ & $66(22)$ & $232(77.3)$ \\
\hline The counseling session has brought change in my perspective about HIVIAIDS & $5(1.7)$ & $135(45)$ & $160(53.3)$ \\
\hline If I had attended HIV counseling sessions earlier, it would had been more beneficial for me & $44(4.7)$ & $213(71)$ & $43(14.3)$ \\
\hline I feel that the counseling session was good & $5(1.7)$ & $79(26.3)$ & $216(72.0)$ \\
\hline The counseling session has not brought change in my perspective about HIVIAIDS & $7(2.3)$ & $150(50)$ & $143(47.7)$ \\
\hline I wish that the counseling sessions had been better & $47(15.7)$ & $224(74.7)$ & $29(9.7)$ \\
\hline
\end{tabular}

ICTC = Integrated Counseling and Testing Centre, HIV = Human immunodeficiency virus

\begin{tabular}{|c|c|c|}
\hline Client satisfaction statements & Median & Mean (SD) \\
\hline $\begin{array}{l}\text { The counselor showed interest in explaining } \\
\text { issues pertaining to HIV that I was not } \\
\text { aware of }\end{array}$ & 3 & $2.92(0.28)$ \\
\hline $\begin{array}{l}\text { During the session I was given the } \\
\text { opportunity to ask questions and clarify my } \\
\text { doubts }\end{array}$ & 3 & $2.68(0.60)$ \\
\hline $\begin{array}{l}\text { The counseling offered to me was very } \\
\text { useful and helpful }\end{array}$ & 3 & $2.76(0.43)$ \\
\hline $\begin{array}{l}\text { The counseling session has brought change } \\
\text { in my perspective about HIVIAIDS }\end{array}$ & 3 & $2.51(0.53)$ \\
\hline $\begin{array}{l}\text { If I had attended HIV counselling sessions } \\
\text { earlier, it would had been more beneficial } \\
\text { for me }\end{array}$ & 2 & $1.99(0.53)$ \\
\hline I feel that the counseling session was good & 3 & $2.70(0.49)$ \\
\hline $\begin{array}{l}\text { The counseling session has not brought } \\
\text { change in my perspective about HIVIAIDS }\end{array}$ & 2 & $2.45(0.54)$ \\
\hline $\begin{array}{l}\text { I wish that the counseling sessions had } \\
\text { been better }\end{array}$ & 2 & $1.94(0.50)$ \\
\hline
\end{tabular}

ICTC = Integrated Counseling and Testing Centre, HIV = Human immunodeficiency virus

$50 \% \cdot{ }^{[9,10]}$ Surprisingly, among the direct walk-in clients, only $13.3 \%$ visited the ICTC due to suspected high risk behavior. This compels the need of creating further awareness about HIV counseling and removing various barriers of clients in visiting ICTC. Due attention has to be paid to increase the direct walk-in clients, as the main purpose of establishment of ICTC could not be served.

The time duration spent in locating the site of ICTC ranged from 1 to $30 \mathrm{~min}$ with a mean time of $10 \mathrm{~min}$. There is a necessity of placing guiding sign boards in ICTC location premises to guide the clients to ICTC thereby reducing any extra time spent in searching the ICTC within the health facility. The median time duration spent by clients in waiting to see the counselor was $15 \mathrm{~min}$. Though this is much lesser when compared to other studies. ${ }^{[8,11]}$ Recruiting additional counselor in the centers where the client load is high could be done liberally to reduce the waiting time. The duration of time spent by clients in the counseling sessions ranged from 2 to $20 \mathrm{~min}$. The time spent during the counseling session could have been adequate for clients to get benefited fully without any unanswered doubts. This would help in reducing the high risk behaviors as well.
The client satisfaction found in the present study was $96.3 \%$. Similar results of client satisfaction were found in some studies. ${ }^{[6,12]}$ However, few studies reported low level of client satisfaction and reasons were due to untrained counselors, low education level of clients, lack of adequate spent time with the counselor, lack of trust in confidentiality, and other barriers. ${ }^{[8,11,13]}$

Though the overall client satisfaction was satisfactory $(96.3 \%)$, certain issues need to be addressed including the waiting time to meet counselors and time spent during the counseling as these determine the quality of the services. Also, few clients reported that they felt hesitant in expressing themselves to the counselor of opposite sex. This suggests the mandatory requirement of both male and female counselors in all the ICTCs.

\section{CONCLUSION}

The proportion of self-referred/direct walk-in clients was very low and low level of awareness about the HIV test and counseling services was found among the clients. This reflects the need to enhance the efforts directed at increasing the awareness of HIV test and counseling services. Though the satisfaction of clients with the counseling services was satisfactory, duration and content of the counseling session shall be improved so that all the clients receive sufficient information during these session with the counselors.

\section{REFERENCES}

1. NACO. NACP III. Annual Report 2011-2012. Available from: http://www. nacoonline.org/upload/REPORTS/NACO/Annual/Report/11-12.pdf. [Last accessed on 2013 Mar 28].

2. GOI, MOHFW, NACO. Operational Guidelines for Integrated Counselling and Testing Centers. 2007;1:1-2.

3. Crane HM, Lober W, Webster E, Harrington RD, Crane PK, Davis TE, et al. Routine collection of patient-reported outcomes in an HIV clinic setting: The first 100 patients. Curr HIV Res 2007;5:109-18.

4. Rashmi, Vijaykumar B. Assessment of the quality of service given by health care provider about tuberculosis in RNTCP. Indian J Community Med 2010;35:368-9.

5. WHO/TB/97.224. WHO Report on the Tuberculosis Epidemic 1997. Use Dots More Widely. Geneva: WHO; 1997.

6. Kabbash IA, Hassan NM, Al-Nawawy AN, Attalla AA, Mekheimer SI. Evaluation of HIV voluntary counselling and testing services in Egypt. Part 1: Client satisfaction. East Mediterr Health J 2010;16:481-90. 
7. UNAIDS. Tools for evaluating HIV voluntary counselling and testing. Available from: http://www.data.unaids.org/Publications/IRC-pub02/ jc685-tools-for-eval_en.pdf. [Last accessed on 2013 Mar 28].

8. Papanna MK, Kumar P, Shetty A, Kamath A, Bhaskaran U, Saddichha S. Client satisfaction with HIV counseling services: A cross-sectional study from south India. J Int Assoc Provid AIDS Care 2013;12:169-72.

9. Gupta M. Profile of clients tested HIV positive in a voluntary counseling and testing Center of a District Hospital, Udupi. Indian J Community Med 2009;34:223-6.

10. Chennaveerappa PK, Halesha BR, Vittal BG, Jayashree N. A Study on the sociodemographic profile of the attendees at the integrated Counselling and Testing Centre of a medical college in south India. J Clin Diagn Res 2011:5:430-3.

11. Lyatuu MB, Msamanga GI, Kalinga AK. Clients' satisfaction with services for prevention of mother-to-child transmission of HIV in Dodoma Rural district. East Afr J Public Health 2008;5:174-9.
12. Department of Health. Ministry of Public Health Thailand. Evaluation of Voluntary Counselling and Testing in the National Prevention of Mother to Child Transmission Programme. Available from: http://www.searo.who. int/Evaluation_of_Voluntary_Counselling_complete.pdf. [Last accessed on 2013 Mar 28].

13. Ginwalla SK, Grant AD, Day JH, Dlova TW, Macintyre S, Baggaley R, et al. Use of UNAIDS tools to evaluate HIV voluntary counselling and testing services for mineworkers in South Africa. AIDS Care 2002;14:707-26.

How to cite this article: Chellaiyan VG, Raut DK, Khokhar A Singh S. Profile and client satisfaction among clients of Integrated Counselling and Testing Centre for human immunodeficiency virus in Delhi. Int J Med Public Health 2014;4:380-4.

Source of Support: Nil, Conflict of Interest: None declared. 